\title{
Primary Hormone Therapy in Elderly Women with Hormone-Sensitive Locoregional Breast Cancer: Endocrine Therapy Alone Is a Reasonable Alternative in Selected Patients
}

\author{
Vanesa Quiroga-García ${ }^{a} \quad$ Beatriz Cirauqui-Cirauqui ${ }^{a} \quad$ Cristina Bugés-Sánchez $^{a}$ \\ Miguel Ángel Luna-Tomás ${ }^{b} \quad$ Eva María Castellà-Fernández ${ }^{c}$ Antonio Mariscal-Martínez ${ }^{d}$ \\ Mireia Margelí-Vila ${ }^{a}$
}

${ }^{a}$ Catalan Institute of Oncology, Hospital Germans Trias i Pujol, Badalona, Spain;

${ }^{b}$ Gynecology and Obstetrics Service, Hospital Germans Trias i Pujol, Badalona, Spain;

c Pathology Service, Hospital Germans Trias i Pujol, Badalona, Spain;

${ }^{\mathrm{d}}$ Radiology Service, Hospital Germans Trias i Pujol, Badalona, Spain

\section{Keywords}

Hormone therapy - Locoregional breast cancer .

Surgery · ER/PR+/HER2-

\section{Summary}

Background: Treatment with aromatase inhibitors (Als) followed by surgery is often recommended for women with locoregional hormone-sensitive breast cancer. However, no study has compared the efficacy of Als alone versus Als followed by surgery. Methods: 33 postmenopausal breast cancer patients were treated with primary hormone therapy. Estrogen receptor (ER), progesterone receptor (PR), and human epidermal growth factor type 2 receptor (HER2) expression levels were analyzed by immunohistochemistry. After hormone therapy, eligible patients underwent surgery, and those who were not candidates for surgery continued on hormone therapy. We retrospectively analyzed time to progression, overall survival, response, and impact of surgery on outcome. Results: All patients were ER+. HER2 was successfully analyzed in 30 patients, all of whom were HER2-. The median time to progression was 94 months, and the median overall survival was not reached, while the mean overall survival was 123 months. The overall response rate was $63.6 \%$, with $9.1 \%$ complete responses. No significant differences in time to progression or survival were observed between patients who underwent surgery and those who did not. Conclusions: Primary hormone therapy with Als is effective in elderly breast cancer patients with high lev- els of hormone receptors and may provide a feasible and tolerable alternative to surgery in selected hormone-sensitive breast cancer patients.

\section{Introduction}

Breast cancer is the most frequently diagnosed cancer and the leading cause of cancer death in women worldwide, accounting for 1.38 million (23\%) new cancer cases and $14 \%$ of the total cancer deaths in 2008 [1]. The incidence of breast cancer is higher among older women, with one-third of the new cases being diagnosed in women over the age of 65 years [2]. Neoadjuvant chemotherapy or hormone therapy followed by surgery is the standard treatment strategy in early-stage breast cancer. Neoadjuvant therapy allows disease control and downstaging of tumors, enabling surgery to be performed in initially unresectable patients and breast-conserving surgery in patients who would otherwise require mastectomy. Although neoadjuvant chemotherapy is recommended in the majority of cases, treatment-related toxicities and the lack of response in certain subtypes of breast cancer make hormone therapy the neoadjuvant treatment of choice in specific subgroups of patients.

Estrogen receptors (ERs) are overexpressed in $60-70 \%$ of breast cancers. Binding of estrogen to the ER stimulates proliferation of mammary cells, leading to cell cycle disruption and, ultimately, tumor formation and growth [3]. ER overexpression is a predictive marker of better response to endocrine treatment, which inhibits

\section{KARGER}

Fax +497614520714

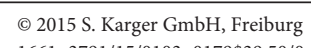


the activation of ER. Progesterone receptors (PRs) are regulated by the ER, and PR+ breast cancers also respond well to hormone therapy [4]. Amplification of the human epidermal growth factor type 2 receptor (HER2), a member of the erbB-like oncogene family, is present in $20-30 \%$ of breast cancers and was a predictor of overall survival and time to relapse [5]. Postmenopausal women aged over 65 years with ER/PR+ and HER2 - tumors are generally considered good candidates for hormone therapy.

Tamoxifen is a selective ER modulator that binds to ERs, thus preventing estrogen from binding. A study comparing tamoxifen alone versus surgery followed by tamoxifen in elderly ( $>70$ years) $\mathrm{ER}+$ breast cancer patients found no differences in overall survival between the 2 groups of patients, although the rate of local relapse was higher in patients treated with tamoxifen without surgery [6]. A later study, with a longer follow-up of up to 12 years, found both a higher relapse rate and shorter overall survival in patients treated with tamoxifen alone [7]. More recently, aromatase inhibitors (AIs), which suppress the synthesis of estrogen, have replaced tamoxifen as the neoadjuvant treatment of choice in postmenopausal women with ER+ breast cancer [8]. Third-generation AIs, such as anastrozol, exemestane, and especially letrozol, have been shown to be more effective than tamoxifen both as neoadjuvant and as adjuvant treatment, attaining higher response rates and higher rates of breast-conserving surgery when used as neoadjuvant treatment [9-15]. To date, however, no study has compared the efficacy of AIs alone versus AIs followed by surgery.

The treatment of elderly breast cancer patients is often complicated by the presence of comorbidities and other factors, including possible cognitive deterioration and concomitant medication, all of which need to be taken into account when deciding on the optimal treatment regimen for each patient [8]. While older age in itself is not sufficient to rule out chemotherapy, radiotherapy, or surgery, the potential adverse effects of these treatments are known to increase with age [16]. Neoadjuvant hormone therapy has been shown to be safe and effective in hormone-sensitive breast cancer patients, making it a feasible option for elderly patients [17]. We hypothesized that, in postmenopausal patients older than 65 years with ER/PR+/HER2 - breast cancer, neoadjuvant hormone therapy may well enable selected patients to avoid surgery.

We therefore retrospectively analyzed response, time to progression, and overall survival in 33 postmenopausal patients with early-stage ER+ breast cancer treated with primary hormone therapy. In addition, we compared outcomes in patients undergoing surgery and in those treated with hormone therapy alone.

\section{Patients and Methods}

\section{Patients}

We retrospectively analyzed 33 postmenopausal patients diagnosed with locoregional ER+ breast cancer in our hospital from 2000 to 2010. All patients gave their signed, informed consent prior to starting treatment. Treatment consisted of AIs in all but 1 patient, who received tamoxifen. The planned duration of neoadjuvant treatment was 6 months. After completion of treatment, clinical response was evaluated by physical examination and mammogram, according to
Table 1. Patient characteristics and response in 33 patients with locoregional ER+ breast cancer treated with hormone therapy

\begin{tabular}{|c|c|}
\hline \multicolumn{2}{|l|}{ Age, years } \\
\hline Median (range) & $79(68-91)$ \\
\hline$<75$ & $10(30.3 \%)$ \\
\hline$\geq 75$ & $23(69.7 \%)$ \\
\hline \multicolumn{2}{|l|}{ Stage } \\
\hline I & $2(6 \%)$ \\
\hline II & $15(45.5 \%)$ \\
\hline III & $16(48.5 \%)$ \\
\hline \multicolumn{2}{|l|}{ Histology } \\
\hline Carcinoma & $7(21.2 \%)$ \\
\hline Invasive ductal carcinoma & $22(66.7 \%)$ \\
\hline Lobular carcinoma & $3(9.1 \%)$ \\
\hline Mucinous & $1(3 \%)$ \\
\hline \multicolumn{2}{|l|}{ Histologic grade } \\
\hline Unknown $^{\mathrm{a}}$ & $13(39.4 \%)$ \\
\hline I & $3(9.1 \%)$ \\
\hline II & $12(36.4 \%)$ \\
\hline III & $5(15.2 \%)$ \\
\hline \multicolumn{2}{|l|}{ ER expression } \\
\hline $10-49 \%$ & $1(3 \%)$ \\
\hline $50-100 \%$ & $32(97 \%)$ \\
\hline \multicolumn{2}{|l|}{ PR expression } \\
\hline $0-19 \%$ & $11(33.3 \%)$ \\
\hline $20-49 \%$ & $6(18.2 \%)$ \\
\hline $50-100 \%$ & $16(48.5 \%)$ \\
\hline \multicolumn{2}{|l|}{ HER2 expression } \\
\hline Negative & $30(92 \%)$ \\
\hline Positive & $0(0 \%)$ \\
\hline No data & $3(9 \%)$ \\
\hline \multicolumn{2}{|l|}{ Primary hormone therapy } \\
\hline Letrozol & $26(78.7 \%)$ \\
\hline Anastrozol & $1(3 \%)$ \\
\hline Exemestane & $5(15.1 \%)$ \\
\hline Tamoxifen & $1(3 \%)$ \\
\hline $\begin{array}{l}\text { Median duration of primary hormone therapy, } \\
\text { months (range) }\end{array}$ & $7.4(6.2-52)$ \\
\hline \multicolumn{2}{|l|}{ Pathological stage } \\
\hline I & $4(19 \%)$ \\
\hline II & $7(33.3 \%)$ \\
\hline III & $10(47.7 \%)$ \\
\hline \multicolumn{2}{|l|}{ Bilateral breast cancer } \\
\hline No & $32(97 \%)$ \\
\hline Yes & $1(3 \%)$ \\
\hline \multicolumn{2}{|l|}{ Surgery } \\
\hline Yes & $21(63.6 \%)$ \\
\hline No & $12(36.4 \%)$ \\
\hline \multicolumn{2}{|l|}{ Type of surgery $(\mathrm{N}=21)$} \\
\hline Mastectomy with axillary clearance & $14(66.6 \%)$ \\
\hline Mastectomy without axillary clearance & $1(4.8 \%)$ \\
\hline Lumpectomy with axillary clearance & $6(28.6 \%)$ \\
\hline \multicolumn{2}{|l|}{ Clinical response $\mathrm{b}^{\mathrm{b}}$} \\
\hline Complete response & $3(9.1 \%)$ \\
\hline Partial response & $18(54.6 \%)$ \\
\hline Stable disease & $7(21.2 \%)$ \\
\hline Progressive disease $e^{c}$ & $5(15.1 \%)$ \\
\hline \multicolumn{2}{|l|}{ Pathological response $^{\mathrm{d}}(\mathrm{N}=21)$} \\
\hline Grade 5 & $0(0 \%)$ \\
\hline Grade 4 & $0(0 \%)$ \\
\hline Grade 3 & $5(23.8 \%)$ \\
\hline Grade 2 & $5(23.8 \%)$ \\
\hline Grade 1 & $11(52.4 \%)$ \\
\hline
\end{tabular}

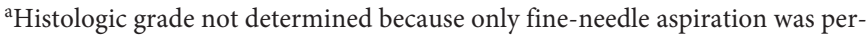
formed.

${ }^{\mathrm{b}} \mathrm{RECIST}$.

c 5 patients progressed: 2 of them during the neoadjuvant treatment; 3 of them after refusing surgery.

${ }^{\mathrm{d}}$ Miller and Payne [19]. 
Table 2. Time to progression and overall survival in surgical and non-surgical patients

\begin{tabular}{lll}
\hline & Surgery $(\mathrm{N}=21)$ & No surgery $(\mathrm{N}=12)$ \\
\hline Mean time to progression, months $(95 \% \mathrm{CI})$ & $82.24(66.62-87.86)$ & $55.42(35.01-75.82)$ \\
Median time to progression, months $(95 \% \mathrm{CI})^{*}$ & $\mathrm{NR}$ & $69.00(19.84-118.16)$ \\
Mean overall survival, months $(95 \% \mathrm{CI})$ & $126.97(110.71-143.23)$ & $77.94(62.38-93.50)$ \\
Median overall survival, months $(95 \% \mathrm{CI})^{* *}$ & $\mathrm{NR}$ & NR \\
\hline
\end{tabular}

NR, Not reached.

${ }^{\star} \mathrm{P}=0.17 ;{ }^{* *} \mathrm{P}=0.38$. the Response Evaluation Criteria in Solid Tumors (RECIST) [18]. After hormone therapy, eligible patients underwent surgery, and those who were not candidates for surgery due to her comorbidities and/or because they refused it continued on hormone therapy until progression or death. Candidates for surgery underwent lumpectomy or mastectomy, and pathological response was evaluated according to the criteria of Miller and Payne [19]. After surgery, all surgical patients continued with hormone therapy for another 5 years. Patients who relapsed during this time continued with hormone therapy or were given chemotherapy or palliative care, according to the criteria of the attending physician.

\section{Immunohistochemistry}

ER and PR expression was determined prior to the decision to administer hormone treatment. HER2 expression was determined as part of the present study. ER, PR and HER2 expression was analyzed by immunohistochemistry (IHC) in tumor samples from the diagnostic biopsy. If positive staining for ER or PR was detected in more than $5 \%$ of tumor cells, the sample was scored as positive. HER2 expression was scored according to the criteria of the Spanish Society of Pathology (SEAP) and the Spanish Society of Medical Oncology (SEOM) for the interpretation of the Herceptest [20]. Samples scored as positive $(2+, 3+)$ were further assessed by fluorescence in situ hybridization (FISH)

\section{Statistical Analyses}

Quantitative variables were shown as absolute frequencies and percentages. Time to progression was calculated from diagnosis until progression or death. Overall survival was calculated from diagnosis until death from any cause. Time to progression and overall survival time, with their $95 \%$ confidence intervals (CIs), were estimated with the Kaplan-Meier method and compared with the log-rank test. All statistical analyses were performed with IBM SPSS (Statistical Package for the Social Sciences) v.20 for MAC OS X. Significance was set at $\mathrm{P} \leq 0.05$.

\section{Results}

\section{Patient Characteristics}

Table 1 shows the characteristics of all the patients. The median age was 79 years (range, 68-91 years), and 23 patients (69.7\%) were 75 years or older. The majority of the patients had stage II (45.5\%) or stage III (48.5\%) disease. 22 (66.7\%) had invasive ductal carcinoma. The histologic grade was I in 3 patients (9.1\%), II in $12(36.4 \%)$ and III in 5 patients (15.2\%). In 13 patients (39\%), the histologic grade could not be determined because only fine-needle aspiration had been performed. 1 patient had bilateral breast cancer at diagnosis.

All patients were ER+; in 32 patients (97\%), ER expression was higher than $50 \%$. PR expression was $50-100 \%$ in 16 patients (48.5\%), $20-49 \%$ in $6(18 \%)$, and $0-19 \%$ in 11 patients $(33.3 \%)$. HER2 was successfully analyzed in 30 patients, all of whom were HER2-

Thirty-two patients (97\%) received AIs: letrozol in 26 patients (78.7\%) and anastrozol or exemestane in the remaining 7 patients. 1 patient received tamoxifen. The median duration of primary hor- mone therapy for the surgery cohort was 7.4 months (range, 6.2-52 months) (table 1).

After completion of primary hormone therapy, 12 patients (36.4\%) who were not candidates for surgery continued hormone therapy until progression, unacceptable toxicity, or death. 21 patients (63.6\%) underwent surgery: mastectomy in 15 (71.5\%) and lumpectomy in 6 cases $(28.5 \%)$. Axillary clearance was performed in all surgical patients except 1 (table 1). After surgery, 4 patients (19\%) were categorized as pathological stage I, 7 (33.3\%) as stage II, and 10 patients $(47.7 \%)$ as stage III (table 1$)$. All surgical patients received adjuvant hormone therapy for 5 years. 11 patients received radiotherapy and 1 patient received adjuvant chemotherapy (5-fluorouracil, epirubicin, and cyclophosphamide plus docetaxel) prior to starting adjuvant hormone therapy.

\section{Response, Time to Progression, and Overall Survival}

Upon completion of neoadjuvant hormone therapy, clinical complete response was observed in 3 patients (9\%), partial response in 18 (54.6\%), and stable disease in 7 patients (21.2\%), for an overall clinical benefit of $84.8 \% .5$ patients (15\%) progressed during hormone therapy (table 1); the median TTP of these was 16 months. 2 of them progressed during the neoadjuvant treatment; one was operated and the other one was not considered for surgery because of her comorbidities. The other 3 patients initially refused surgery and continued with the hormone therapy, receiving a median of 32.7 months of treatment before accepting surgery due to progression. Grade 3, 2, and 1 responses were observed in $23.8 \%$, $23.8 \%$, and $52.4 \%$ of the 21 surgical patients, respectively (table 1 ).

With a mean follow-up of 62 months (range, 6.7-139.4 months) for the entire cohort, the median time to progression was 94 months (95\% CI, 81.2-106.8 months) (fig. 1A). The time to progression in surgical patients was not reached, compared to 69 months (95\% CI, 19.8-118.1 months) in those who did not undergo surgery $(\mathrm{P}=12)$ (table 2, fig. $1 \mathrm{~B})$.

The median survival was not reached for the entire cohort (fig. 2A), while the mean overall survival was 123 months (95\% CI, 108-137 months). The mean overall survival was 126 months (95\% CI, 110.7-143.2 months) in the surgical patients and 78 months (95\% CI, 62.3-93.5 months) in those who did not undergo surgery $(\mathrm{P}=12)$ (table 2, fig. 2B).

During follow-up, 27 patients (82\%) remained disease free. 6 patients had metastases; bone metastases occurred in 4 and liver metastases in 3 patients. Other metastatic sites were the pleura (2), lymph nodes (2), lung (2), and peritoneum (1). 4 patients died from causes not related to cancer, 2 of whom were disease free at the time of death. 
Fig. 1. Time to progression in (a) the entire cohort of 33 patients and (b) in 21 patients who underwent surgery versus 12 patients who did not.

Fig. 2. Overall survival in (a) the entire cohort of 33 patients and $(\mathbf{b})$ in 21 patients who underwent surgery versus 12 patients who did not. The median overall survival was not reached in any of these groups.
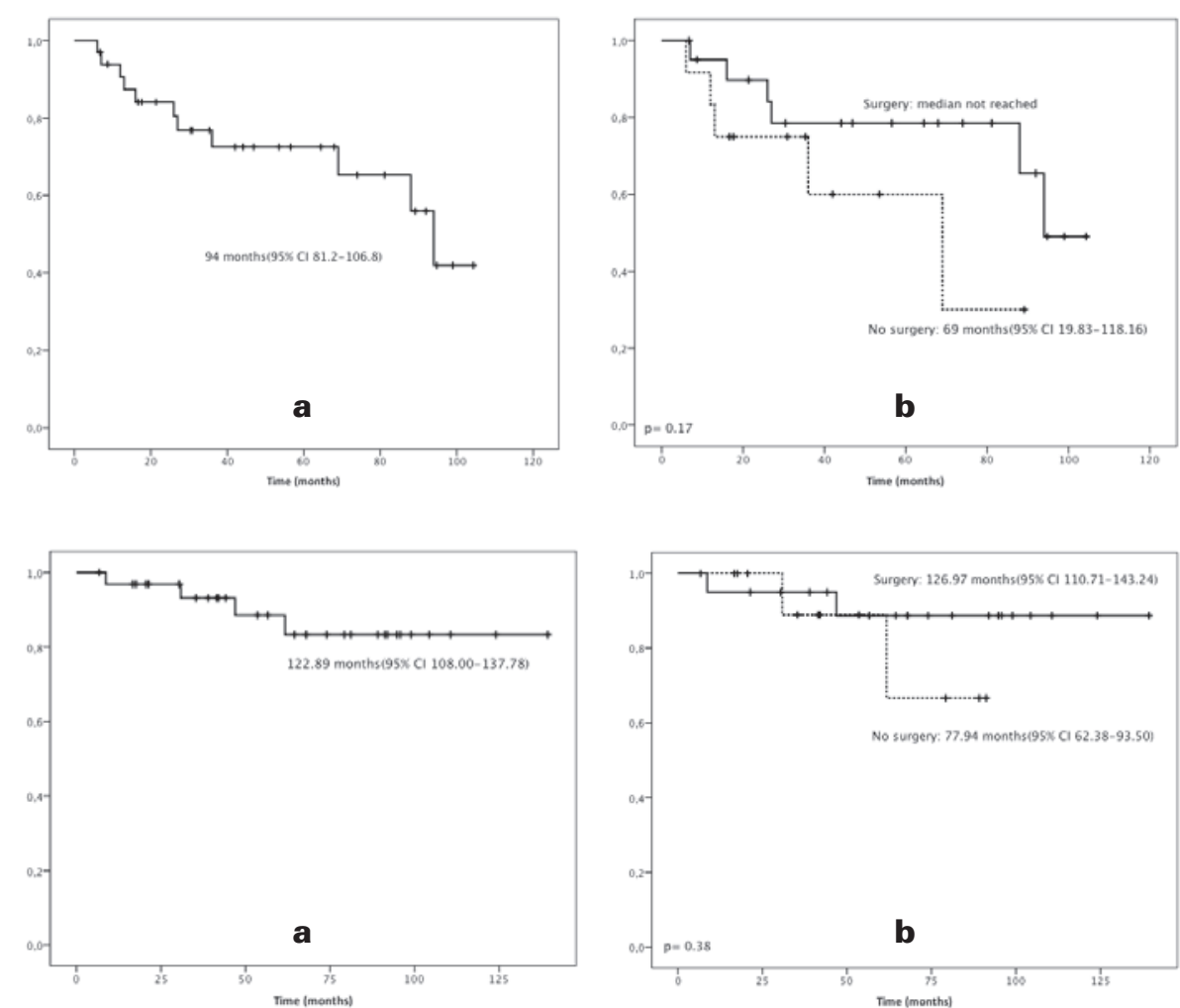

\section{Discussion}

Breast cancer is a heterogeneous disease and is considered a more indolent disease in the elderly, who are less tolerant of aggressive therapy and who often have comorbidities [8]. At the same time, however, elderly patients often show higher expression of hormone receptors. The median age of our series of patients was 79 years, and $48.5 \%$ of the patients were diagnosed with stage III disease and $45.5 \%$ with stage II. This is in line with general epidemiological data indicating that older breast cancer patients tend to be diagnosed with more advanced stages of the disease [21]. While the risk of treatment-related adverse events often leads physicians to rule out chemotherapy in elderly patients, hormone therapy is an effective and safe option in elderly patients with ER/PR+/HER2breast cancer, and response rates are comparable to those obtained with neoadjuvant chemotherapy in selected groups of patients [22].

The outcomes in the present study were generally in line with previous reports. The clinical response rate was $63.7 \%$, including 3 complete responses, but no complete pathological responses were observed. Both of these findings are in agreement with previous studies $[13,15]$, which reported clinical response rates of $58-76 \%$ but infrequent complete pathological responses in ER/PR+/HER2breast cancer. The median time to progression in the present study was 94 months, and only 6 patients had metastases, 4 (29\%) of whom had bone metastases, which have been linked to hormonesensitive breast cancer [23]. The median overall survival was not reached, while the mean overall survival was 123 months, and at the time of analysis, only 4 patients had died, none due to cancerrelated causes. The majority of our patients were ER/PR+, and
HER2 expression was negative in all 30 patients in whom it was successfully analyzed. In addition to this favorable ER+/HER2status, we suggest that the type of hormone therapy may have contributed to these superior outcomes, since the majority of patients received AIs, which have been shown to be more efficacious than tamoxifen [9-15].

Importantly, no significant differences in time to progression or overall survival were observed between surgical and non-surgical patients. A previous study comparing tamoxifen alone versus surgery followed by tamoxifen also found no differences in overall survival during the first 12 years of follow-up $[6,7]$. In the present study, the median age of the patients was 79 years, and physicians must weigh this uncertain survival benefit against the increased risks of surgery in elderly patients when deciding on treatment options for these patients.

Endocrine therapy with AIs alone is not an alternative but a justified and reasonable therapy strategy with encouraging time to progression and overall survival in elderly patients with ER-positive breast cancer who are at high risk for surgery-associated morbidity and mortality or who refuse surgery. Despite the retrospective nature and the small sample size of our study, our findings provide a rationale for the use of hormone therapy in elderly patients with ER+/HER2- breast cancer, which warrants examination in a larger patient cohort.

\section{Disclosure Statement}

The authors received no funding for this study and declare no conflicts of interest. 


\section{References}

1 Ferlay J, Shin HR, Bray F, Forman D, Mathers C, Parkin DM: Estimates of worldwide burden of cancer in 2008: GLOBOCAN 2008. Int J Cancer 2010;127:28932917.

2 Landis SH, Murray T, Bolden S, Wingo PA: Cancer statistics, 1998. CA Cancer J Clin 1998;48:6-29.

3 Yager JD, Davidson NE: Estrogen carcinogenesis in breast cancer. N Engl J Med 2006;354:270-282.

4 Allred DC, Harvey JM, Berardo M, Clark GM: Prognostic and predictive factors in breast cancer by immunohistochemical analysis. Mod Pathol 1998;11:155-168.

5 Slamon DJ, Clark GM, Wong SG, Levin WJ, Ullrich A, McGuire WL: Human breast cancer: correlation of relapse and survival with amplification of the HER-2/ neu oncogene. Science 1987;235:177-182.

6 Mustacchi G, Ceccherini R, Milani S, Pluchinotta A, De Matteis A, Maiorino L, et al.: Tamoxifen alone versus adjuvant tamoxifen for operable breast cancer of the elderly: long-term results of the phase III randomized controlled multicenter GRETA trial. Ann Oncol 2003; 14:414-420.

7 Fennessy M, Bates T, MacRae K, Riley D, Houghton J, Baum M: Late follow-up of a randomized trial of surgery plus tamoxifen versus tamoxifen alone in women aged over 70 years with operable breast cancer. $\mathrm{Br} \mathrm{J}$ Surg 2004;91:699-704.

8 Macaskill EJ, Renshaw L, Dixon JM: Neoadjuvant use of hormonal therapy in elderly patients with early or locally advanced hormone receptor-positive breast cancer. Oncologist 2006;11:1081-1088.

9 Barnadas A, Gil M, Gonzalez S, Tusquets I, Munoz M, Arcusa A, et al.: Exemestane as primary treatment of oestrogen receptor-positive breast cancer in postmenopausal women: a phase II trial. Br J Cancer 2009;100: 442-449.
10 Eiermann W, Paepke S, Appfelstaedt J, Llombart-Cussac A, Eremin J, Vinholes J, et al.: Preoperative treatment of postmenopausal breast cancer patients with letrozole: A randomized double-blind multicenter study. Ann Oncol 2001;12:1527-1532.

11 Ellis MJ, Ma C: Letrozole in the neoadjuvant setting: the P024 trial. Breast Cancer Res Treat 2007;105(suppl 1):33-43.

12 Ellis MJ, Miller WR, Tao Y, Evans DB, Chaudri Ross HA, Miki Y, et al.: Aromatase expression and outcomes in the P024 neoadjuvant endocrine therapy trial. Breast Cancer Res Treat 2009;116:371-378.

13 Ellis MJ, Suman VJ, Hoog J, Lin L, Snider J, Prat A, et al.: Randomized phase II neoadjuvant comparison between letrozole, anastrozole, and exemestane for postmenopausal women with estrogen receptor-rich stage 2 to 3 breast cancer: clinical and biomarker outcomes and predictive value of the baseline PAM50-based intrinsic subtype - ACOSOG Z1031. J Clin Oncol 2011; 29:2342-2349.

14 Smith IE, Dowsett M, Ebbs SR, Dixon JM, Skene A, Blohmer JU, et al.: Neoadjuvant treatment of postmenopausal breast cancer with anastrozole, tamoxifen, or both in combination: the Immediate Preoperative Anastrozole, Tamoxifen, or Combined with Tamoxifen (IMPACT) multicenter double-blind randomized trial. J Clin Oncol 2005;23:5108-5116.

15 Semiglazov V, Kletsel A, Semiglazov V, Zhiltzova E, Ivanov V, Dashyan G, et al.: Exemestane (E) vs tamoxifen (T) as neoadjuvant endocrine therapy for postmenopausal women with ER+ breast cancer (T2N1-2, T3N0-1, T4N0M0). ASCO Annual Meeting 2005; abstr 23.
16 Yancik R, Wesley MN, Ries LA, Havlik RJ, Edwards BK, Yates JW: Effect of age and comorbidity in postmenopausal breast cancer patients aged 55 years and older. JAMA 2001;285:885-892.

17 Ellis MJ: Preoperative endocrine therapy for older women with breast cancer: renewed interest in an old idea. Cancer Control 2000; 7:557-562.

18 Eisenhauer EA, Therasse P, Bogaerts J, Schwartz LH, Sargent D, Ford R, et al.: New response evaluation criteria in solid tumours: revised RECIST guideline (version 1.1). Eur J Cancer 2009;45:228-247.

19 Ogston KN, Miller ID, Payne S, Hutcheon AW, Sarkar TK, Smith I, et al.: A new histological grading system to assess response of breast cancers to primary chemotherapy: prognostic significance and survival. Breast 2003;12:320-327.

20 Albanell J, Andreu X, Calasanz MJ, Concha A, Corominas JM, Garcia-Caballero T, et al.: Guidelines for HER2 testing in breast cancer: a national consensus of the Spanish Society of Pathology (SEAP) and the Spanish Society of Medical Oncology (SEOM). Clin Transl Oncol 2009;11:363-375.

21 Yancik R, Ries LG, Yates JW: Breast cancer in aging women. A population-based study of contrasts in stage, surgery, and survival. Cancer 1989;63:976-981.

22 Semiglazov VF, Semiglazov VV, Dashyan GA, Ziltsova EK, Ivanov VG, Bozhok AA, et al.: Phase 2 randomized trial of primary endocrine therapy versus chemotherapy in postmenopausal patients with estrogen receptor-positive breast cancer. Cancer 2007;110:244-254.

23 Coleman RE, Rubens RD: The clinical course of bone metastases from breast cancer. Br J Cancer 1987;55 61-66. 